\title{
Urban gardening as a means for fostering embodied urban human-food connection? A case study on urban vegetable gardens in Germany
}

\author{
Martina Artmann ${ }^{1} \mathbb{D} \cdot$ Katharina Sartison ${ }^{1} \cdot$ Christopher D. Ives $^{2}$
}

Received: 19 June 2020 / Accepted: 19 January 2021 / Published online: 25 February 2021

(c) The Author(s) 2021

\begin{abstract}
Urbanization is increasingly compromising residents' connection to natural habitats and landscapes. With established relationships between human-nature connection (HNC) and pro-environmental behaviour and human well being, there are calls for effective interventions to strengthen $\mathrm{HNC}$ in urban settings. However, much of this research has operationalised HNC in narrow psychological terms. Based on an embodied framework of urban human-food connection (HFC) as a specific dimension of HNC, this article explores the role of active urban gardening in promoting different types of internal and external HFC and their link with pro-environmental food behaviour (PEFB). Based on a quantitative survey in Germany addressing vegetable gardeners in Munich $(N=254)$, a principal component analysis extracted four components of HFC comprising external body-related HFC (i.e. immediate urban garden-body activities: food harvesting and experiential food interaction) and internal mind-related HFC (i.e. immediate urban garden-mind activities including food discovery as well as food consciousness). These were found to be statistically related to one another. Furthermore, regression analysis revealed that food consciousness through concerns on food consumption and environmental impacts as well as food as part of life attitude as an internal HFC is the sole predictor of PEFB. The study suggests an embodied HFC model emphasizing the need for local bodyand mind-based nature connections for fostering earth stewardship. Future research should explore the relationship between inner dimensions of nature connectedness and external behavioural change to enable transformations towards sustainability.
\end{abstract}

Keywords Urban food production · Human-nature connection · Pro-environmental behaviour · Sustainable development · Urban gardening

\section{Introduction}

In our rapidly urbanising world, people are increasingly detached from nature (Hartig and Kahn 2016). Taking into consideration that the share of people living in cities

Handled by Lars Coenen, University of Melbourne, Australia.

Martina Artmann

m.artmann@ioer.de

Katharina Sartison

k.sartison@ioer.de

Christopher D. Ives

chris.ives@nottingham.ac.uk

1 Leibniz Institute of Ecological Urban and Regional Development, Weberplatz 1, 01217 Dresden, Germany

2 School of Geography, University of Nottingham, Nottingham NG7 2RD, UK is projected to increase from 55 to $68 \%$ by 2050 (United Nations 2019), the individual and societal consequences of humanity's isolation from nature are in need of urgent attention. Urbanisation decreases access to green space and nature experience (Cox et al. 2018; Lin et al. 2015), which is crucial for mental and physical health of city residents suffering from stressful urban environments (Bratman et al. 2012; Engemann et al. 2019). Another field of research has shown the value of nature connectedness in terms of the clear link between human-nature connection (HNC) and pro-environmental behaviour (PEB) (Braito et al. 2017; Frantz and Mayer 2014; Whitburn et al. 2018). PEB can be defined as an activity by one person or group, which promotes or results in a sustainable consumption of natural resources (Sivek and Hungerford 1990). In the face of pressing environmental challenges such as climate change and biodiversity loss, understanding human behaviour and attitudes is key to foster sustainable development (Martin et al. 
2016; McKenzie-Mohr and Schultz 2014). In this regard, $\mathrm{HNC}$ is discussed in the current sustainability research as a vital leverage for sustainability transformation. It requires further research to understand the characteristics of interventions and in how far they increase HNC, which in turn might effect change (Abson et al. 2017; Ives et al. 2018).

\section{An embodied perspective on human-nature connection}

$\mathrm{HNC}$ has become a topic of research attention from fields as disparate as environmental psychology, conservation biology, environmental education and sustainability science (Clayton and Myers 2010; Frantz and Mayer 2014; Ives et al. 2017; Nisbet et al. 2009). Psychological measures have been particularly prominent as a methodological approach for assessing HNC (Cleary et al. 2018; Lin et al. 2015; Scopelliti et al. 2016). To capture what it means to be connected to nature, current research in this field has emphasized the need to develop a multidimensional understanding of $\mathrm{HNC}$, taking into account different internal human cognitive or affective responses about and towards nonhuman nature (Hatty et al. 2020; Tam 2013; Whitburn et al. 2019). However, to further overcome the human-nonhuman, mind-matter and subject-object dichotomies that obfuscate integrated forms of sustainability research and practice, there have been calls for more relational forms of sustainability research that integrate internal and external relationships with nature (Walsh et al. 2021; West et al. 2020). Indeed, the recent scholarship has emphasised the need for an embodied HNC approach that conceptualises $\mathrm{HNC}$ as an interplay between internal and external human and nonhuman nature including mind, body, environment and culture (Colding et al. 2020; Cooke et al. 2016; Raymond et al. 2017). An embodied approach takes into account that "(...) humans are not just mentally, but also materially and physically immersed in their immediate environments" (Cooke et al. 2016, p. 2). In the context of sustainability transitions, an embodied perspective of HNC therefore emphasises that "people and societies are integrated parts of the biosphere, depending on its functioning and life support while also shaping it globally" (Folke 2011, p. 719) (see Cooke et al. 2016).

As a way of organising the breadth of internal and external HNC dimensions and relating them to sustainability transformation, Ives et al. (2018) proposed five HNC dimensions. These extended along a spectrum from external to internal HNC. Material connections (i.e. for instance the need to extract and use resources) and experiential connections (e.g. through recreational use of green landscapes) can be understood as external ways by which humans connect with nonhuman nature. Cognitive connections such as beliefs and knowledge as well as emotional (referring to personal attachment to nature) and philosophical connections (related to how humans conceive of their relationship to the Earth) can be understood as internally-defined connections to nature. Given the fact that research on various HNC dimensions is still in its infancy, recent studies have called for further exploration, in particular taking into account the neglected external material dimension of HNC (Hatty et al. 2020). In this regard, Artmann et al. (2020) applied the framework by Ives et al. (2018) introducing the concept of Human-Food Connection (HFC) as an interpretation of $\mathrm{HNC}$ in the context of local food production and consumption. Urban food production and associated practices, such as urban gardening have been proposed as potential interventions to strengthen $\mathrm{HNC}$ in cities (Colding et al. 2020; Cooke et al. 2016; Turner 2011). As a focus of considerable research attention, many studies have suggested that by participating in community gardens or allotments, urban residents can profit from mental and physical well being, healthy food production, social cohesion and environmental learning (Breuste and Artmann 2015; Camps-Calvet 2016; Kingsley et al. 2009). In contrast, the study on HFC in an edible city in Germany by Artmann et al. (2020) showed that while spaces of food production increased attractiveness and place identity, residents rarely used the free food provided by the city administration on public spaces, limiting external and internal embodied connections to nonhuman nature and food. Thus, more research is needed to understand the dimensionality of urban HFC (Artmann et al. 2020) and the role of active urban gardening as a potential 'lever' to foster urban HNC (Ives et al. 2018).

\section{Human-nature connection as a means of promoting sustainable human behaviour and system transformation}

HNC can be conceptualized as a 'leverage point' for system change, while recognising that, in practice, different HNCs are often intertwined. A strengthening of different types of $\mathrm{HNC}$ can precipitate positive impacts for sustainability at differing levels of influence. For example, strengthening internal HNC, such as emotional and philosophical connections have potential to bring about deep change to system behaviour, as such connections relate to system goals and paradigms. In contrast, focusing on external material or experiential connections to nature may improve human well being and reduce physical environmental impacts, but on their own may not bring about system-wide transformative change (Ives et al. 2018).

To strengthen HNC research in the context of sustainability, further research is needed to explore different types of HNC (Abson et al. 2017; Ives et al. 2018) and investigate how internal and external embodied HNC experiences manifest in sustainability practices (Cook et al. 2016). Indeed, human behaviour change is a critical component 
of sustainability transformations (Klaniecki et al. 2019). Klaniecki et al. (2018) proposed that effective interventions for deep systemic change should promote interaction with local nature that fosters " $(\ldots)$ responsibility to protect nature around the globe through their lifestyle and consumption behaviors" (Klaniecki et al. 2018, p. 1382). Following Klaniecki et al. (2019), we understand HNC as an avenue for (re-)connecting urban residents with nature aiming at transforming human behaviour towards sustainability.

In the context of PEB and urban gardening as potential interventions strengthening HNC (see "the an embodied perspective on human-nature connection"), studies suggest that urban gardening can influence consumer behaviour in favour of organic, regional and seasonal food consumption (Winkler et al. 2019). However, such findings are not conclusive. For instance, active organic gardening has been found not to translate into the purchasing of organic food (Turner 2011). In general, food is recognised as cross-cutting issue and a crucial action area for sustainability transformation (Wolfram et al. 2016). It is therefore evident that urban gardening has potential to influence urban sustainability in multidimensional ways, as it intersects with issues of land use, nature experiences, environmental behaviours and the production and consumption of food. Consequently, there is a need to further analyse the link between various types of HNC, PEB and urban gardening practices.

\section{Research objectives and paper outline}

Inspired by Ives et al. (2018), who called for further research on the interactions among and transformational potential of various HNC types, this study aims to evaluate urban vegetable gardening as an embodied practice that develops internal and external HFC as an interpretation of HNC and shapes behaviour. The study applies the multidimensional framework of HFC by Artmann et al. (2020) which was developed in the context of edible cities (see "the an embodied perspective on human-nature connection"), and responds to their recommendation for more in-depth studies on HFC dimensions. Our objectives are to (i) explore different external and internal types of HFC in the context of an urban agricultural setting via a quantitative survey in Munich (Germany), and (ii) investigate how these relate to Pro-Environmental Food Behaviour (PEFB) of garden users.

This paper is organized as follows: "the case study section" presents the case study in Munich, while "the methods" conceptually outlines HFC and its association with PEFB as well as detailing the survey instrument. Main results are presented in "the results", which considers sociodemographic factors that can influence urban gardeners' gardening experiences and behaviours (Philpott et al. 2020). In "the discussion", we discuss the findings with a special focus on analysing relationships between HFC dimensions identified. Main conclusions are drawn in Sect. "the conclusion".

\section{Case study}

Munich is the third biggest city in Germany with a population of approximately 1.5 million inhabitants (Munich 2019). It is the capital of Bavaria and incorporates the main economic centre in southern Germany. Munich has had a population increase of $8.6 \%$ between 2011 and 2018 contributing to its high population density of 4912 inhabitants $/ \mathrm{km}^{2}$ (State Statistics Bavaria 2019). In 2013 Munich had the smallest area of green space per capita of all German major metropolitan regions. Each inhabitant has $77 \mathrm{~m}^{2}$ of parks, agricultural areas, forests and waterways available. A comparison with Hamburg $\left(206 \mathrm{~m}^{2} /\right.$ capita) or Berlin $\left(105 \mathrm{~m}^{2} /\right.$ capita $)$ shows the need for public green space (Munich 2015). The long-term settlement development strategy by the city government sees potential in food production through urban gardening projects, such as municipal vegetable gardens ("Krautgärten") (Munich 2013).

Vegetable gardens are a common project between farmers, the City of Munich and Munich residents. Vegetable gardens refer to plots of peri-urban agricultural land turned into organic vegetable gardens in spring, which are rented to residents who take care of the garden between April and November (Munich 2016). Farmers provide fields that can be annually rented by citizens, who take care of the garden in the season. The plots have a size of either 30 or $60 \mathrm{~m}^{2}$ and on $60 \mathrm{~m}^{2}$ plot a gardener harvest approximately $200 \mathrm{~kg}$ of vegetables (Munich 2016). A specific share of the plot is already cultivated by the farmers with vegetables, while the residents can cultivate the rest with young plants, also provided by the farmers. Currently, 26 sites with vegetable gardens can be found in and around the city as part of this project (see Fig. 1) whereby the city of Munich targets to increase the number of the gardens annually (Munich 2017).

\section{Methods}

\section{Conceptualising human-food connection and pro-environmental food behaviour}

To explore which types of internal and external embodied HFC dimensions are promoted through active urban gardening and their links with PEFB, our framework is based on the work by Artmann et al. (2020). Grounded in a city-wide survey, their overall framework analysed one of the first edible cities in Germany and its impacts on the 


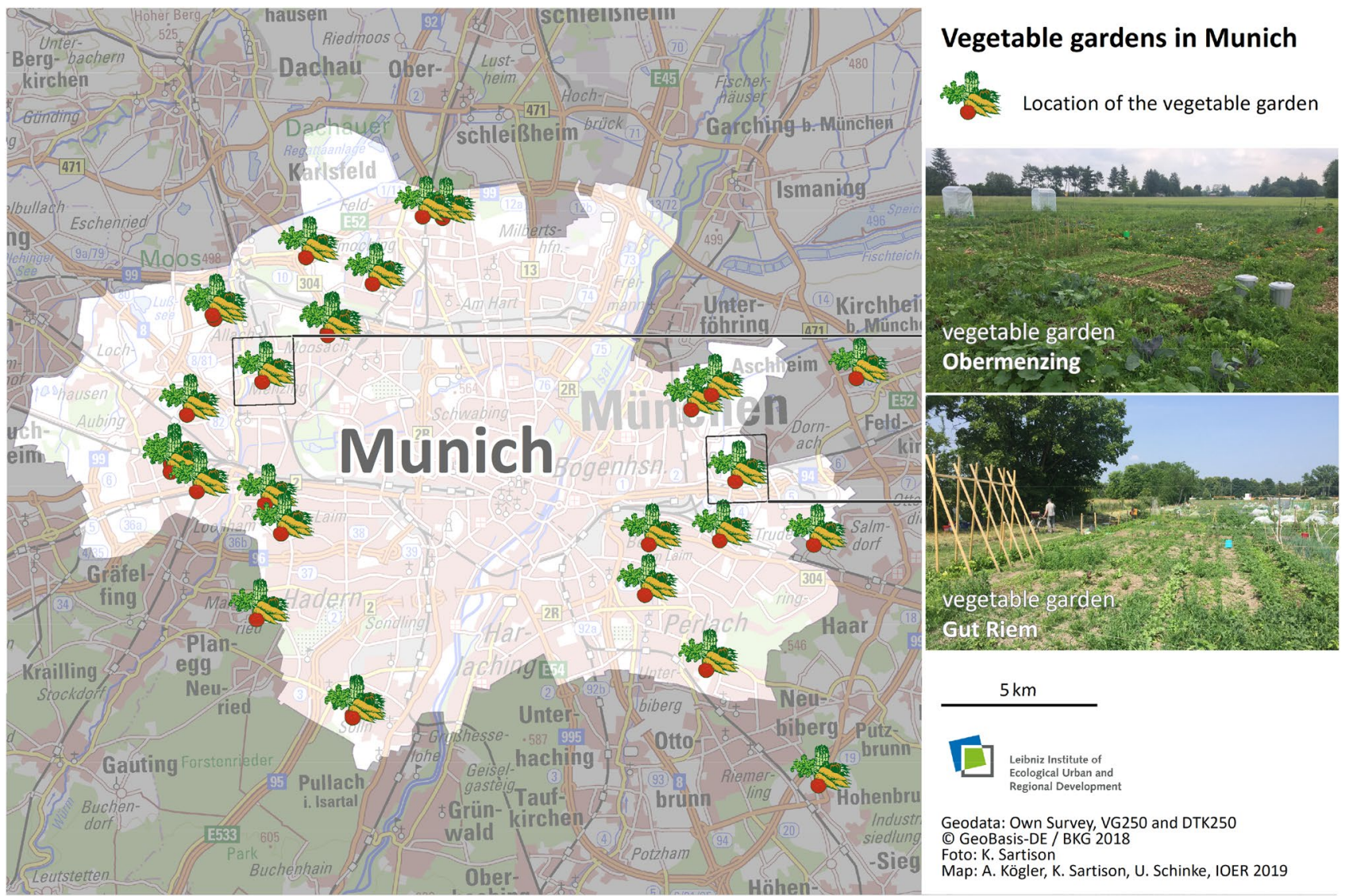

Fig. 1 Map of Munich and its vegetable gardens

local population in terms of place attachment, HFC and PEFB. Artmann et al. (2020) extended the HNC typology by Ives et al. (2018) to define various external and internal connections with food and food-growing landscapes.

The present study responds directly to the call by Artmann et al. (2020) to further explore the dimensionality of HFC. Thus, the original framework by Artmann et al. (2020) had a broader scope, taking into account the role of place attachment (including its dimensions place dependence, place identity, social and nature bonding), HFC and PEFB, but the authors did not analyse various HFC dimensions nor their relationships to PEFB in depth. Their findings revealed that residents of the edible city rarely use the edible plants on public spaces resulting in partly high missing value rates of items related with HFC. Therefore, the authors recommend further in-depth studies focusing on urban residents actively engaging in urban gardening and to test if HFC can be considered as a multidimensional construct (ibd.). Therefore, by excluding the role of place attachment related with urban food production, our analyses focus solely on HFC, its potential various dimensions, and their relationship with PEFB of active vegetable gardeners.
Building on the survey items suggested for the HFC framework by Artmann et al. (2020), this study further conceptualized HFC by suggesting an embodied approach taking into account three concepts in the context of urban gardening practices: internal HFC, external HFC, and PEFB (see Fig. 2). Internal HFC involves cognitive and emotional processes as well as philosophical associations connected with urban gardens and food production in general. The embodied cognition, which links body, mind and environment (Raymond et al. 2017), was captured in the survey by queries asking for knowledge gained through gardening (related with diet or other ecological topics such mobility) and urban gardeners' attitudes related with the harvested food assessing if the food grown in the vegetable garden is very healthy or tasty.

Internal emotional and philosophical HFC include feelings of deep connection to nature when spending time in the urban garden and worldviews reflecting on concerns related with impacts on nature due to food production (e.g. in how far animals and plants shall be available for human food production or thinking about how food consumption affects the environment while consuming food). External HFC includes activities related with the food harvested (i.e. the share of 
Fig. 2 Conceptual basis of the embodied HFC approach and examples of its survey operationalization (icon made by Freepix from www.flati con.com). (Note: All survey items are found in the Online Appendix)

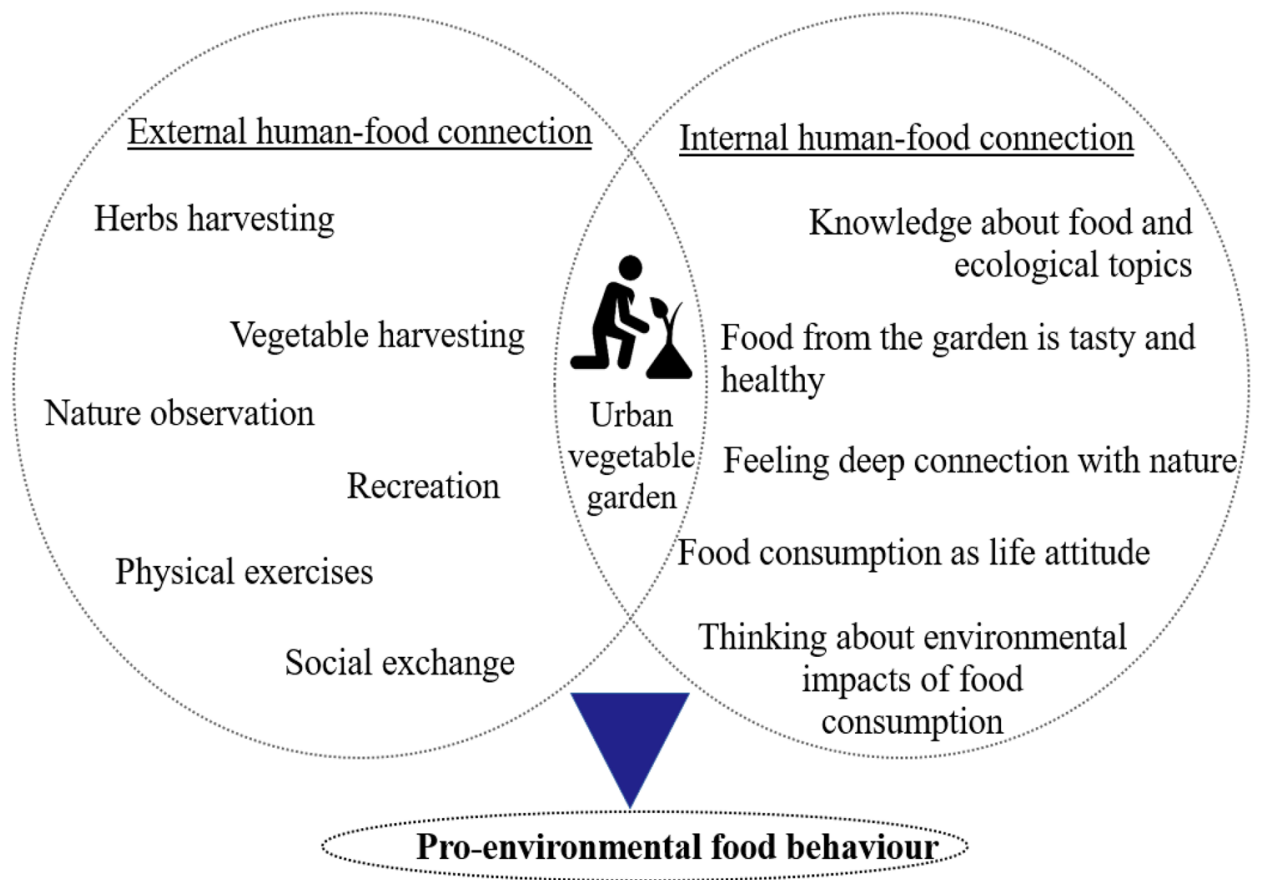

vegetables/herbs/fruits harvested from the vegetable garden in comparison to the share purchased in the supermarket) and direct experiences of the edible landscapes and their enjoyment captured by the frequency of using the edible areas for nature observations, recreation, physical exercises and socialising. Consumer food behaviour was evaluated as an assessment of PEFB. PEFB variables were based on those studied by Artmann et al. (2020), namely items referring to buying seasonal, regional and exotic food.

HNC dimensions cannot always be neatly partitioned. Indeed, Hatty et al. (2020) found that cognitive, emotional, and behavioural elements can be represented through a single environmental identity dimension. As such, we designed the study without defining the HFC categories a priori. By doing so, we aimed to explore the full spectrum of embodied HFC taking into account external and internal dimensions, their relationships between each other and impacts on PEFB (see Fig. 2).

\section{Data collection}

Based on the HFC and PEFB conceptualisation by Artmann et al. (2020), a questionnaire was designed. While Artmann et al. (2020) focused on a city scale (i.e. edible city), items of our survey were adapted to our case study focusing on a specific case of an edible landscape component, namely vegetable gardeners in Munich, Germany. Five-point Likert scales were used to assess HFC and PEFB related to urban gardening. A single item on purchasing exotic food was reverse coded for analysis to ensure that high scores indicated high PEFB.
For implementing and extracting our multidimensional HFC concept, we conducted an online survey with users of the vegetable gardens in Munich by using SoSciSurvey (https://www.soscisurvey.de). Such a web-based questionnaire serves as a resource-efficient way for contacting a high number of people in a short time period outside of the gardening season (Winkler et al. 2019). The link to the questionnaire was sent via e-mail to contact persons of each vegetable garden asking them to forward the questionnaire to all members of the vegetable garden projects (snowball sampling) (Creswell 2009). Furthermore, one vegetable garden coordinator was nominated to promote the survey during a kick-off meeting with vegetable gardeners for the gardening season in March 2019. The questionnaire was online between February and May 2019. For ethical reasons, an inhouse data protection manager was involved in developing the questionnaire. The questionnaire was pre-tested by two experts from the city government and one farmer providing the land for the vegetable gardens. Based on their remarks the questionnaire was slightly adapted and sent out to the addressees.

In total, 254 gardeners answered the questionnaire completely, which equates to a response rate of $17 \%$ if assuming that a) all gardeners were addressed and b) one vegetable garden patch belongs to one response. In sum, we received responses from 19 out of 26 vegetable gardens which encompass in sum 1,521 garden patches (Munich 2018). The share of females with $74.8 \%$ is much higher than the share of male gardeners with $25.2 \%$. Compared with the local demographic composition of the area, proportionally more females than men completed the survey (female: $51 \%$, 
male: $49 \%)$. The mode age within the survey was between 42 and 53 years $(36.6 \%$; $\mathrm{SD}=1.047)$ and lies slightly above the average age in Munich which is 41.2 years (Munich 2019). However, the comparison with regional statistics cannot be regarded as representative since the target group of this study are the vegetable gardeners. To the authors' knowledge, there are no statistical data on their population structure.

\section{Data analysis}

Firstly, descriptive statistics were calculated for questionnaire responses using IBM SPSS Statistics 25. As categories of HFC items were not defined a priori, we conducted a Principal Component Analysis (PCA) with varimax rotation to explore the statistical grouping of variables. PCA is a type of exploratory factor analysis, which explains the maximum amount of a common variance based on a correlation matrix taking into account the smallest number of explanatory factors (Field 2000). PCA is a well-suited method to identify dimensionalities of human-nature relationships and is for instance used for conceptualizing dimensions of place attachment (Raymond et al. 2010) and HNC (Hatty et al. 2020).

If more than $10 \%$ of the respondents selected as an alternative answer option "I do not know", items were handled as missing values and were deleted (Schlomer et al. 2010). The Kaiser-Meyer-Olkin measure of sampling adequacy was 0.783 , which shows a relatively good measure for the PCA and Bartlett's test of Sphericity was significant $(p<0.001)$. According to Hammitt et al. (2000)'s criteria, we formed factors as follows: Eigenvalues $\geq 1.0$, factor loadings $\geq 0.40$, and items loading on more than one factor had to differ by 0.10 in loading to be kept in the PCA (see Raymond et al. 2010). We created summated scales and analysed the itemto-total and inter-item correlation between the extracted factors. Reliability analysis was executed to examine the internal consistency (Cronbach's alpha) of the items for each dimension of HFC.

In order to measure in how far the HFC dimensions predict PEFB, we conducted bivariate correlations between the mean response scores of the extracted HFC dimensions and further assessed these with a linear regression analysis to identify HFC dimensions predicting PEFB. The model shows no auto-correlation as the value of the Durbin-Watson statistic is 1.996 (Gujarati and Porter 1999) and all other pre-requisites for regression analysis, such as standard distribution, multicollinearity or homoscedasticity of variance are met.

All items, their detailed scales and identified dimensions after the data analyses can be found in the Online Appendix.

\section{Results}

The PCA identified four HFC dimensions with eigenvalues exceeding 1 , which accounted for $62.0 \%$ of the total variance. Among the component solutions, the varimaxrotated four-factor solution yielded the most interpretable results and most items loaded highly on these four with suitable reliabilities (Lambda2 $\geq 73$ ) constituting cohesive HFC subscales (Callender \& Osburn 1979). The four dimensions encompassed two external HFC, i.e. food interaction and food harvesting, and two internal HFC, i.e. food consciousness and food discovery, based on 14 of 20 possible HFC items (see Table 1).

Overall, all HFC dimensions were rated highly by survey respondents. Their grand means ranged from 3.39 (both for experiential food interaction and food harvesting) to 4.13 (food discovery as cognitive HFC) up to 4.37 (food consciousness). Thus, residents use the urban vegetable gardens regularly for harvesting food (and therefore for physical exercises) leading also to high shares of picked vegetables and herbs compared to the food bought in the supermarket. Overall, respondents evaluated that the self-produced food in the vegetable garden was tasty and healthy, and were in generally highly aware of the connection between food production and environmental impacts. These findings were emphasised by a comment by an urban gardener added at an open comment field in the end of the questionnaire: "The vegetable garden is one step towards a conscious living (....). I think that we have adapted our eating habits. We eat what is seasonally growing (...). Vegetables from the supermarket are not tasty anymore since a long time".

Regression analyses of relationships between HFC dimensions and PEFB revealed that the linear combination of the predictor variables was significant $F(4,205)=7.59$, $p<0.001$. The coefficient of determination $\left(R^{2}\right)$ was 0.11 , indicating that $11 \%$ of the variance in PEFB was accounted for by these variables, representing a moderate effect size (Cohen, 1988). As presented in Table 2, results show that food consciousness was a significant predictor of PEFB $(\beta=0.26, \mathrm{SE}=0.06, \mathrm{t}(208)=3.51, p<0.001)$. However, the other three extracted HFC dimensions show no significant relationships to PEFB.

Bivariate correlations with socio-demographic and other urban gardening related variables show mostly only weak relationships. The correlations showed positive but low significant correlations between the length of patch rental and food consciousness $(r=0.15, p<0.05)$ and food harvesting $(r=0.20, p<0.01)$. In terms of gender, women had stronger food consciousness scores $(r=0.15, p<0.05)$, experiential food interaction $(r=0.14, p<0.05)$ and food harvesting 
Table 1 Principal component analysis of human-food connection dimensions in vegetable gardens of Munich

\begin{tabular}{|c|c|c|c|c|}
\hline Component and its items & \multirow[t]{2}{*}{ Factor loading } & Grand mean & Item mean & $\begin{array}{l}\text { Standard } \\
\text { deviation }\end{array}$ \\
\hline Food interaction [EXT] (Eigenvalue $=4.20 ;$ Variance explained: $30.0 \%)$ & & 3.39 & & \\
\hline $\begin{array}{l}\text { How often do you use the vegetable garden } \\
\text { for nature observation? }\end{array}$ & 0.83 & & 3.11 & 1.06 \\
\hline $\begin{array}{l}\text { How often do you use the vegetable garden } \\
\text { for recreation purpose? }\end{array}$ & 0.77 & & 3.20 & 1.11 \\
\hline $\begin{array}{l}\text { How often do you use the vegetable garden } \\
\text { for physical exercise? }\end{array}$ & 0.74 & & 3.64 & 0.72 \\
\hline $\begin{array}{l}\text { How often do you use the vegetable garden } \\
\text { for picking food? }\end{array}$ & 0.43 & & 3.82 & 0.55 \\
\hline Food consciousness $[$ INT] $($ Eigenvalue $=1.93$; variance explained: $13.8 \%)$ & & 4.37 & & \\
\hline $\begin{array}{l}\text { While consuming food, I think about } \\
\text { how my food consumption affects the } \\
\text { environment. }\end{array}$ & 0.88 & & 4.22 & 0.84 \\
\hline $\begin{array}{l}\text { I know the connection between food pro- } \\
\text { duction and environmental impacts. }{ }^{\text {b }}\end{array}$ & 0.76 & & 4.56 & 0.59 \\
\hline $\begin{array}{l}\text { My food consumption is part of my life } \\
\text { attitude. }^{\text {b }}\end{array}$ & 0.76 & & 4.33 & 0.85 \\
\hline Food discovery [INT] (Eigenvalue $=1.36$; variance explained: $9.7 \%)$ & & 4.13 & & \\
\hline $\begin{array}{l}\text { The food grown in the vegetable garden is } \\
\text { very healthy. }\end{array}$ & 0.79 & & 4.67 & 0.57 \\
\hline $\begin{array}{l}\text { The food grown in the vegetable garden } \\
\text { tastes very good. }\end{array}$ & 0.76 & & 4.76 & 0.51 \\
\hline $\begin{array}{l}\text { By using the vegetable garden, I learn a } \\
\text { lot about other ecological topics (e.g. } \\
\text { in the area of mobility, consumption, } \\
\text { travelling). }\end{array}$ & 0.59 & & 3.09 & 1.24 \\
\hline $\begin{array}{l}\text { By using the vegetable garden, I learn a lot } \\
\text { about food and diet. }\end{array}$ & 0.57 & & 4.01 & 1.04 \\
\hline Food harvesting $[E X T]$ (Eigenvalue $=1.19$; Variance explained: $8.5 \%)$ & & 3.39 & & \\
\hline $\begin{array}{l}\text { How high is the share of herbs you get from } \\
\text { the vegetable garden in comparison to the } \\
\text { share you buy in the supermarket? }^{c}\end{array}$ & 0.87 & & 3.4 & 1.06 \\
\hline $\begin{array}{l}\text { How high is the share of vegetables you get } \\
\text { from the vegetable garden in comparison } \\
\text { to the share you buy in the supermarket? }\end{array}$ & 0.81 & & 3.4 & 1.30 \\
\hline
\end{tabular}

External HFC dimensions are indicated by [EXT] and internal HFC dimensions by [INT]

${ }^{\mathrm{a}}$ Items were measured on a five-point Likert scale ranging from $1=$ never, $2=$ sometimes, $3=$ more than once a month, $4=$ more than once a week, $5=$ daily

${ }^{b}$ Items were measured on a five-point Likert scale ranging from $1=$ strongly disagree, $2=$ rather disagree, $3=$ neutral, $4=$ rather agree, $5=$ strongly agree

${ }^{\mathrm{c}}$ Items were measured on a five-point Likert scale ranging from $0 \%, 1-25 \%, 26-50 \%, 51-75 \%, 76-100 \%$ (referring to the amount of food picked from the areas cultivated with edible plants in comparison to the food bought in the supermarket)

scores $(r=0.15, p<0.05)$ compared to male respondents. Interestingly, education showed a weak but negative correlation with food interaction $(r=-0.20, p<0.05)$ and cognitive HFC presented through food discovery $(r=-0.14, p<0.05)$ meaning that urban gardeners with lower education had a higher HFC. Age of the urban gardeners was not correlated with any HFC dimensions (see Table 3).

\section{Discussion}

\section{Relationships between urban human-food connection dimensions}

This study has examined different types of internal and external HFC of urban vegetable gardeners and how HFC is related to PEFB. Four different types of HFC were distinguished: food harvesting and experiential food interaction 
Table 2 Regression analysis for variables predicting PEFB (N=209)

\begin{tabular}{lllll}
\hline Variable & $\mathrm{B}$ & $\mathrm{SE}_{\mathrm{B}}$ & $\beta$ & $p$ \\
\hline Constant & 2.37 & .30 & - & .000 \\
Food consciousness [INT] & .23 & .06 & .26 & .001 \\
Food discovery [INT] & .10 & .07 & .12 & .119 \\
Food interaction [EXT] & .011 & .06 & .01 & .869 \\
Food harvesting [EXT] & -.07 & .04 & .13 & .078 \\
\hline
\end{tabular}

$\mathrm{R}^{2}=.11$

External HFC dimensions are indicated by [EXT] and internal HFC dimensions by [INT] as forms of external HFC, and food discovery and food consciousness as internal expressions of HFC. This suggests that practices of active urban gardening encompass various dimensions of HFC. The fact that various HNC dimensions do not operate in isolation but are related to one another (sensu Ives et al. 2018), was supported by correlations among the extracted HFC dimensions (see Table 4). This supports conclusions by Tam (2013) and Whitburn et al. (2019) that measuring HNC by multidimensional scales such as cognitive and affective ones is important for understanding and determining interventions promoting greater
Table 3 Correlations between HFC, PEFB and other urban gardening variables

\begin{tabular}{|c|c|c|c|c|c|}
\hline Variable & $\begin{array}{l}\text { Food conscious- } \\
\text { ness [INT] }\end{array}$ & $\begin{array}{l}\text { Food discov- } \\
\text { ery [INT] }\end{array}$ & $\begin{array}{l}\text { Food interac- } \\
\text { tion }[\mathrm{EXT}]\end{array}$ & $\begin{array}{l}\text { Food harvest- } \\
\text { ing }[\mathrm{EXT}]\end{array}$ & PEFB \\
\hline \multicolumn{6}{|l|}{ PEFB } \\
\hline Pearson correlation $r$ & $.35^{\mathrm{b}}$ & $.22^{\mathrm{b}}$ & .01 & -.03 & 1 \\
\hline$N$ & 242 & 225 & 228 & 228 & 228 \\
\hline \multicolumn{6}{|c|}{ Length of patch rental ( $1=1$ season, $21=21$ seasons $)$} \\
\hline Pearson correlation $r$ & $.15^{\mathrm{a}}$ & -.06 & .03 & $.20^{\mathrm{b}}$ & .006 \\
\hline$N$ & 251 & 233 & 238 & 229 & 241 \\
\hline \multicolumn{6}{|c|}{ Frequency of patch use $(1=$ Never to $5=$ Daily $)$} \\
\hline Pearson correlation $r$ & .12 & $.22^{\mathrm{b}}$ & $.55^{\mathrm{b}}$ & $.25^{\mathrm{b}}$ & -.008 \\
\hline$N$ & 252 & 234 & 239 & 239 & 242 \\
\hline \multicolumn{6}{|c|}{ Age $(1=18-29,2=30-41,3=42-53,4=54-65,5=66-77,6=\geq 78$ years $)$} \\
\hline Spearman correlation $r$ & .08 & .08 & .11 & .11 & .02 \\
\hline$N$ & 252 & 234 & 239 & 239 & 242 \\
\hline \multicolumn{6}{|c|}{ Gender $(1=$ male, $2=$ female $)$} \\
\hline Spearman correlation $r$ & $.15^{\mathrm{a}}$ & .10 & $.14^{\mathrm{a}}$ & $.15^{*}$ & .02 \\
\hline$N$ & 248 & 230 & 239 & 239 & 238 \\
\hline \multicolumn{6}{|c|}{$\begin{array}{l}\text { Education }(1=\text { no education certificate, } 2=\text { secondary school leaving certificate, } 3=\text { baccalaureate, } \\
\quad 4=\text { university degree })\end{array}$} \\
\hline Spearman correlation $r$ & -.02 & $-.14^{\mathrm{a}}$ & $-.20^{\mathrm{a}}$ & -.11 & .11 \\
\hline$N$ & 242 & 234 & 239 & 239 & 238 \\
\hline
\end{tabular}

External HFC dimensions are indicated by [EXT] and internal HFC dimensions by [INT]

${ }^{\text {a }}$ Correlation is significant at the .05 level (2-tailed)

${ }^{\mathrm{b}}$ Correlation is significant at the .01 level (2-tailed)

\begin{tabular}{llllll}
\hline & & $\begin{array}{l}\text { Food } \\
\text { harvesting } \\
{[\text { EXT] }}\end{array}$ & $\begin{array}{l}\text { Food } \\
\text { interaction } \\
{[\text { EXT] }}\end{array}$ & $\begin{array}{l}\text { Food } \\
\text { discovery } \\
{[\text { INT] }}\end{array}$ & $\begin{array}{l}\text { Food con- } \\
\text { sciousness } \\
{[\text { [NT] }}\end{array}$ \\
\hline Food harvesting [EXT] & Pearson correlation $r$ & 1 & $.33^{\mathrm{a}}$ & $.18^{\mathrm{a}}$ & $.19^{\mathrm{a}}$ \\
& $\mathrm{N}$ & 239 & 233 & 222 & 238 \\
Food interaction [EXT] & Pearson Correlation r & $.33^{\mathrm{a}}$ & 1 & $.42^{\mathrm{a}}$ & $.25^{\mathrm{a}}$ \\
& $\mathrm{N}$ & 233 & 239 & 223 & 238 \\
Food discovery [INT] & Pearson Correlation r & $.18^{\mathrm{a}}$ & $.42^{\mathrm{a}}$ & 1 & $.39^{\mathrm{a}}$ \\
& $\mathrm{N}$ & 222 & 223 & 234 & 233 \\
Food consciousness [INT] & Pearson Correlation r & $.19^{\mathrm{a}}$ & $.25^{\mathrm{a}}$ & $.39^{\mathrm{a}}$ & 1 \\
& $\mathrm{~N}$ & 238 & 238 & 233 & 252 \\
\hline
\end{tabular}

${ }^{\mathrm{a}}$ Correlation is significant at the .01 level (2-tailed)

External HFC dimensions are indicated by [EXT] and internal HFC dimensions by [INT] 
PEB. Interestingly, when comparing the four extracted HFC dimensions, the correlations suggest that in particular food harvesting as a 'body-oriented' HFC has the strongest and positive correlation with food interactions as another physical HFC. Food consciousness as a 'mind-oriented' HFC is significantly and positively correlated with food discovery as another cognitive dimension of HFC. While there appears to be a distinction between external 'body-oriented' and internal 'mind-oriented' food connections, all four HFC dimensions have significant positive relationships with each other. The weakest relationship can be found for food harvesting and food discovery $(r=0.18, p<0.01)$; the strongest relationship was between food interaction and food discovery $(r=0.42, p<0.01)$. Thus, food interaction might be considered as an intermediary or 'translating' form of nature connection that links body-oriented and mind-oriented HFC.

However, the correlations do not necessarily infer causal relationships, and it is likely that bi-directional interactions exist among HFC dimensions. Indeed, this interconnected, multi-relational ontology is central to a systems perspective on human-ecological phenomena (Folke et al. 2016). For instance, the positive relationship between urban gardeners' attitudes towards food and frequency of experiential garden use can be supported by findings of Lin et al. (2014). They found that in particular nature orientation is a strong determinant of visiting urban parks compared to green space accessibility (Lin et al. 2014). However, the frequent use of the vegetable gardens for experiential food interactions can also be a consequence of more mind-based HFC such as positive attitudes towards self-grown food. Further, results from a study by Soga et al. (2019, p. 357) suggest “(...) that people with a stronger inclination towards nature sought out more experiences with wild flowering plants." Future research is needed to understand how various dimensions of HFC influence each other.

\section{Relationships between urban gardeners' characteristics and urban human-food connection}

Bivariate correlations with sociodemographic data show positive but weak significant correlations between the length of patch rental and food consciousness $(r=0.15, p<0.05)$ and food harvesting $(r=0.20, p<0.01)$. These findings can be discussed through the lens of sense of place as embodied experience (West et al. 2020), describing relationships between individuals and their specific environments (e.g. Giuliani and Feldman 1993; Raymond et al. 2010). Place attachment is discussed as an important factor for strengthening HNC (Ives et al. 2017; Klaniecki et al. 2018) and environmental stewardship (Gottwald and Stedman 2020). Related studies suggest that place attachment evolves over time and depends among other things on the length of residence (Jorgensen and Stedman 2006). Also, the time spent in nature positively influences emotional affinity towards nature (Kals et al. 1999). Our findings show that the frequency of using vegetable gardens is significantly and positively associated with body-related HFC, in particular experiential food interaction $(r=0.55, p<0.1)$ and food harvesting $(r=0.25, p<0.1)$. This is perhaps to be expected given the conceptual similarity of the concepts. However, the relationship does support the potential for a pathway for reconnecting people to nature, whereby frequent interaction with nature can foster lifestyles and diverse practices based on nature (Ives et al. 2018).

Some differences were observed between results from this study and findings by Artmann et al. (2020). Internal and external HFC appeared strong in our case, with data depicting frequent resident engagement with urban food production. Conversely, Artmann et al. (2020) reported that edible areas providing free food on public spaces were rarely used (see "the introduction"). The present study showed that vegetable gardeners harvest more vegetables and thereby use the garden more often for physical exercise and learn more about food and diet through active gardening compared to residents of the edible city (Artmann et al. 2020). Since the two studies used different case studies and methodological approaches (e.g. comparison of a selected focus group in Munich vs. the whole population in the edible city Andernach), any conclusions that active urban gardening is more efficient for promoting HFC than implementing urban gardens in a city with lacking civic participation, is not conclusive. Thus, further in-depth investigations under similar study conditions are needed.

Correlation between the HFC dimensions, gender and education show only small effect sizes. Between age and HFC no relationships were found at all supporting the findings by Cleary et al. (2018) that HNC interventions are important for older and younger people. Gender differences in HFC were small but significant, with women having stronger HFC regarding food consciousness $(r=0.15$, $p<0.05)$, experiential food interaction $(r=0.14, p<0.05)$ and food harvesting $(r=0.15, p<0.05)$. In fact, women identify in another case study as lifestyle gardeners prioritizing plant diversity, experiential activities and communing with the nature in the garden (Taylor et al. 2017). These indications pave the way to connect the HNC debate with the partnership with nature discourse and its linkages with feminism (Knippenberg et al. 2018) suggesting that women are closer to nature than men (Roach 1991). This may also explain why more women (74\%) than men participated in the survey (25\%) suggesting that more women are gardening than men, such as also found in another German-wide study (Winkler et al. 2019). Some previous studies reflecting the role of gender in urban food production found that drivers for engaging in urban agriculture do not differ between 
men and women but that female gardeners in particular see themselves benefiting of stress relief compared to men (Robertson 2013). Taking into account that urban conditions such as noisy and crowded environments can be considered as being in particular stressful (Hartig and Kahn 2016), health benefits perceived by female gardeners might be one explanation for why women particularly engaged in urban vegetable gardens in a big city such as Munich. In terms of any relationship between psychological well-being and PEB, Whitburn et al. (2018) assumed that urban HNC can strengthen mental benefits, which might translate into PEB, or in our case internal food consciousness. Further research analysing drivers of female urban food producers are the need of women to secure supplementary source of food in Cameroon (Ngome and Foeken 2012) or to overcome any racial and class-based barriers such as by black women activists in Detroit, US (White 2011). Since both issues where not relevant for this case study, it needs future research analysing why women are participating in urban gardening in Central Europe compared to men.

The weak but significant negative correlation between food discovery and education may indicate that residents with lower levels of formal education benefit more greatly from urban gardens. A similar result was shown in a case study in Barcelona, Spain (Camps-Calvet et al. 2016). In fact, evaluating $\mathrm{HNC}$ is a crucial variable to assess the effectiveness of environmental education programs (Frantz and Mayer 2014).

\section{The role of food consciousness}

The regression analysis showed that food consciousness was the only HFC dimension significantly related to PEFB. Further, only the HFC dimension was statistically correlated with all the other dimensions (harvesting, interaction and discovery) (see "the relationships between urban human-food connection dimensions"). These findings provide evidence for both the conceptual and empirical distinction between HFC dimensions, and their inherent relatedness. Closer examination of the items that comprise this dimension revealed possible explanations for why only food consciousness was related to PEFB. The items that loaded on this factor represent life attitudes, awareness and concerns related with food consumption without linking directly to the specific vegetable garden. Thus, the dimension can be considered as representing 'indirect' nature connections (Soga and Gaston 2020), possibly related to notions of environmental identity (Clayton 2003). In fact, the strength measured between $\mathrm{HNC}$ and PEB can be influenced by taking into account items that indirectly measure PEB, such as environmental identity (Hatty et al. 2020; Whitburn et al. 2019). Thus, a comprehensive meta-analysis of scientific studies assessing relationship between HNC and PEB by Whitburn et al. (2019) showed that scales using such items correlate more strongly with PEB than scales without including such items.

In contrast to food consciousness representing 'indirect' nature connections and mediating PEFB, the three HFC dimensions food harvesting, food interaction and food discovery can be considered a more immediate human-nature interaction explicitly referring to the vegetable gardens. The negative relationships found between food harvesting and PEFB, and between frequency of patch use and PEFB (albeit nonsignificant), may be explained by urban gardeners who harvest more and use the garden more frequently, requiring less purchased food. In this regard, analysing different HFC dimensions and their impact on PEFB need to be context-specific, taking into account the close interplay between direct HFC via food harvesting and indirect HFC as sustainable food consumption. Thus, food self-provisioning can be considered a PEFB in terms of a positive future-oriented and transformation-enabling everyday practice " $(. .$. by subjects who consciously reflect on and challenge the food system's deleterious social and environmental effects." (Jehlička et al. 2019, p. 513). This sentiment was expressed by an urban resident who commented in the end of the survey: s/he supported the urban vegetable garden project as a way of strengthening ecological agriculture and environmental education, considering this to be an activity that was simultaneously meaningful and enjoyable.

This statement together with the crucial role of food consciousness fostering PEFB can also be reflected under the well-known slogan "think globally, act locally". In this regard, our findings suggest that immediate HFC (namely local urban gardening and its producing immediate urban garden-body- and mind-related HFC-dimensions) is related to a broader sphere of HFC (characterising interconnections between local action and wider global environmental impacts displayed by food consciousness) that in turn is translated into PEFB. Thus, food consciousness and its related items mainly reflect concerns of food consumption and environmental impacts as well as food as part of life attitude. Indeed, other studies found that individuals' selfperception about pro-environmental concerns are crucial for predicting PEB (Carfora et al. 2017). Lumber et al. (2017, p. 5) suggested that: “(..) the desire to protect nature may not be a result of connectedness solely, but serves as a route to connectedness in its own right". This calls for more research to capture the full complexity of HNC taking into account positive feelings such as joy in nature and negative emotions when it comes to nature destruction and coping with global and local environmental loss (Chawla 2020).

These findings fit well into the debate on an embodied $\mathrm{HNC}$ and its role for fostering earth stewardship. Cooke et al. (2016) emphasised that global sustainability needs local entry points that can be entered by combining acting 
Fig. 3 An embodied model for human-food connection on the example of urban vegetable gardens (adapted from Raymond et al. 2017, icon made by Freepix from www.flaticon. com)

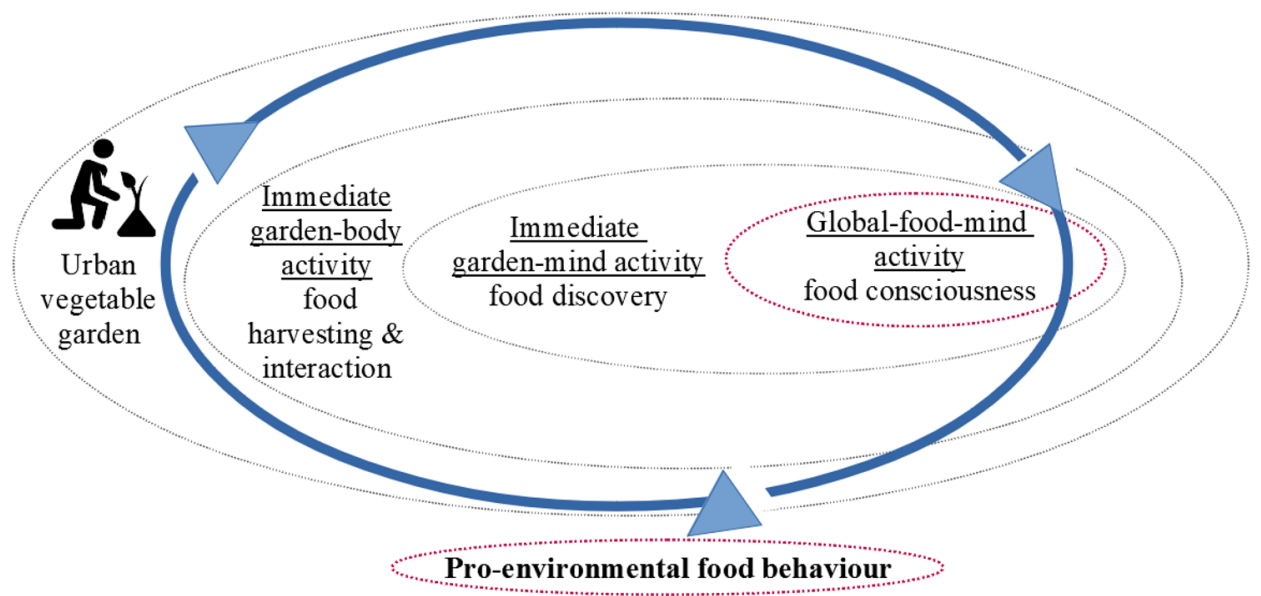

(here: body-related HFC including food harvesting and food interaction) and thinking (here: mind-related HFC including food discovery and food consciousness) in our everyday surroundings that are in our case study the urban vegetable gardens (see Fig. 3). Therefore, based on our results, we suggest that there is a possible causal pathway from (i) experiential, 'external' connections with food landscapes that develop (ii) an 'internal' consciousness of the importance of food personally and ecologically, leading to (iii) behaviours that express this consciousness. Exploring this pathway in more depth is an avenue for future research, especially the importance of developing sustainability mindsets in order to bring about behaviour change. For example, nature and sustainability education programs should not only provide mindbased information, but should consist of theory and practice. Ideas from deep ecology can provide effective practical exercises to foster awareness of self and nature in the immediate nature such as through nature blessing, sensual nature observation or mimicking animals (Kowalewski 2002). In terms of urban planning and development our study supports the call by Colding et al. (2020, p. 7): "Planners and urban designers need to foster arenas in cities that promote collective action and where urban residents can interact with nature more fundamentally with their heads, hands and heart.“

In this regard, interventions for fostering strong urban HNC and PEB should not only take into account vegetable gardens and their active gardeners. In general, urban residents are considered to lack nature experience harming the appreciation of the natural world (Soga and Gaston 2016). According to Klyen et al. (2020), urban residents connect in terms of their knowledge, emotions or behaviours with various formal and informal urban green spaces and its elements, such as with river corridors, home gardens or trees. For children, private gardens are most preferred spaces to connect with nature (Hand et al. 2017). In this regard, urban gardening projects such as in Munich can be considered crucial activities for compensating in cities often lacking private gardens. Statements from survey participants found in the open comment field in the end of the questionnaire support this assumption. For instance, one participant emphasised that her/his child loves to join the vegetable garden for harvesting since lacking a private garden for similar nature experiences. Another gardener expressed a desire for their own garden, which cannot be realised due to high rental prices, but was compensated through renting a vegetable garden. Beyond the need to compensate for a lack of private green spaces, urban gardening projects can be a valuable entry point to attract various kinds of urban residents, who might be interested in learning about or contributing to urban gardening techniques, socializing, healthy food or nature protection. Thus, urban food production has sufficient upscaling potential as a mean for fostering HFC and sustainability transformation (Sartison and Artmann 2020).

\section{Study limits and future research}

Limitations were related to our study methodology. First, by conducting an online survey spread by contact persons, urban gardeners without email contact or not involved in the mailing list, might not have been reached. However, to reduce this risk the survey was additionally promoted during a kick-off meeting for the gardening season in March 2019. Secondly, to capture PEFB the results are based on self-reported estimates on actual behaviour. Future research could further validate this by using assessment methods such as diaries used for analysing patterns of food consumption through a time series (Cheng et al. 2007).

Thirdly, the study focuses on urban vegetable gardens, therefore we do not claim that the findings can be transferred to all types of urban food production. Recent research suggests that various types of urban gardens, such as community, allotment or oyster gardens support environmental stewardship (Andersson et al. 2014; Krasny et al. 2014; Langemeyer et al. 2018). However, if there are any 
difference between types of urban gardens and their impact on various HNC dimensions and PEB needs further in-depth research whereby our framework can function as an analytical framework.

Since food consciousness as mind-based HFC is in our study a key predictor for PEFB, we suggest that future research should further elaborate on how to assess and record internal HNC. In general, to deepen the understanding of PEB, recent research claims that sustainability science needs to put more weight on the neglected inner lives of individuals as a means to sustainability transformation (Ives et al. 2020). Since our variable explaining food consciousness provides only weak correlations with PEFB, future research should consider related psychological concepts such as biocentric or ecocentric values (Dietz et al. 2005), and exploring urban gardening and consumer behaviours from a social practice perspective (Strengers and Maller 2015). Besides input for theory-action education programs, ideas related to deep ecology and its associated concept of the ecological self, emphasizing that all human and nonhuman objects are interconnected in a vast web of relationships (Bragg 1996; Naess 1973), can provide insights on how to further elaborate on internal $\mathrm{HNC}$ in the context of transforming human behaviour towards sustainability. Moreover, to foster creativity and inter- and transdisciplinary sustainability research that can be constrained by often abstract scientific language (see also Ives et al. 2020), we suggest that future urban $\mathrm{HNC}$ research should explore more greatly the "inner human nature" by linking the research subject (urban residents and their inner world such as mental wellbeing, personal values and worldviews) and object (external nonhuman nature such as urban gardens).

\section{Conclusion}

Understanding different types of urban HNC is key to develop successful interventions for transforming human behaviour towards sustainability. In this paper, various internal and external dimensions for analysing HFC as an interpretation of $\mathrm{HNC}$ and a cross-cutting issue in sustainability science were identified on the example of urban vegetable gardeners in Munich. A PCA revealed four components of HFC with high construct validity and reliability comprising external body-related HFC (including food harvesting and food interaction) and internal mind-related HFC (including food discovery and food consciousness). All dimensions were found to be statistically related to one another. The regression analysis revealed that food consciousness described through concerns on food consumption and environmental impacts as well as food as part of life attitude is the sole predictor for explaining PEFB proofing the importance of internal connections with nature as leverage for PEFB and thus, sustainability transformation. Weak but most significant positive correlations with this predictor were found with the length of patch rental and female gardeners linking to discourses related with the role of place attachment and gender in the light of sustainable development. Reflections of the results show that implementing edible areas in a city that are rarely used by the residents can lead to lower HFC compared to residents who are actively engaged in urban gardening. To understand relationships between different HFC dimensions and PEFB, we developed an embodied HFC model emphasizing the need for local body- and mind-based nature experiences for fostering global earth stewardship. Thus, our study suggests that nature and sustainability education programs should strengthen environmental identity by linking mindbased information with practical nature experience. To further explore internal forms of human-nature experience, future research can work with deep ecology to outweigh the dichotomy between humans and nature. By doing so, future research can identify successful practical and theoretical interventions for fostering an intimate relationship between the "inner human nature" of urban residents and the external nature as a basis for sustainability transformation that considers nature as worthy of protection. In this regard, urban gardening projects can be considered a valuable entry point for transforming human behaviour towards sustainability by attracting urban residents with various interests in food production.

Supplementary Information The online version contains supplementary material available at https://doi.org/10.1007/s11625-021-00911-4.

Acknowledgements The authors would like to thank all vegetable gardeners who participated in the survey. Furthermore, we are grateful to all local stakeholders who provided us with valuable information on the vegetable gardens in Munich and who distributed the survey link to our target group. We thank two anonymous reviewers for their valuable comments, which helped to improve this paper.

Author contribution MA: conceptualization, methodology, writing original draft, visualization, supervision, project administration, funding acquisition. KS: investigation, formal analysis, data curation, writing — original draft, visualization. CDI: validation, writing—review and editing.

Funding Open Access funding enabled and organized by Projekt DEAL. This project is funded by the Deutsche Forschungsgemeinschaft (DFG, German Research Foundation) (Grant number: AR 1121/1-1). Artmann's work has also been funded by the Leibniz Competition (J76/2019).

\section{Compliance with ethical standards}

Conflicts of interest The authors declare no conflicts of interest.

Open Access This article is licensed under a Creative Commons Attribution 4.0 International License, which permits use, sharing, 
adaptation, distribution and reproduction in any medium or format, as long as you give appropriate credit to the original author(s) and the source, provide a link to the Creative Commons licence, and indicate if changes were made. The images or other third party material in this article are included in the article's Creative Commons licence, unless indicated otherwise in a credit line to the material. If material is not included in the article's Creative Commons licence and your intended use is not permitted by statutory regulation or exceeds the permitted use, you will need to obtain permission directly from the copyright holder. To view a copy of this licence, visit http://creativecommons. org/licenses/by/4.0/.

\section{References}

Abson DJ, Fischer J, Leventon J, Newig J, Schomerus T, Vilsmaier U, Jager NW (2017) Leverage points for sustainability transformation. Ambio 46(1):30-39. https://doi.org/10.1007/ s13280-016-0800-y

Andersson E, Barthel S, Borgström S, Colding J, Elmqvist T, Folke C, Gren A (2014) Reconnecting cities to the biosphere: stewardship of green infrastructure and urban ecosystem services. Ambio 43:445-453. https://doi.org/10.1007/s13280-014-0506-y

Artmann M, Sartison K, Vávra J (2020) The role of edible cities supporting sustainability transformation: a conceptual multi-dimensional framework tested on a case study in Germany. J Clean Prod 255:120220. https://doi.org/10.1016/j.jclepro.2020.120220

Bragg EA (1996) Towards ecological self: deep ecology meets constructionist self-theory. J Env Psychol 16(2):93-108

Braito MT, Böck K, Flint C, Muhar A, Muhar S, Penker M (2017) Human-nature relationships and linkages to environmental behaviour. Environ Values 26(3):365-389. https://doi.org/10.3197/ $096327117 X 14913285800706$

Bratman GN, Hamilton JP, Daily GC (2012) The impacts of nature experience on human cognitive function and mental health. Ann NY Acad Sci 1249(1):118-136. https://doi.org/10.1111/j.17496632.2011.06400.x

Breuste JH, Artmann M (2015) Allotment gardens contribute to urban ecosystem service: case study Salzburg, Austria. J Urban Plann Dev 141(3):A5014005. https://doi.org/10.1061/(ASCE)UP.19435444.000026

Callender JC, Osburn H (1979) An empirical comparison of coefficient alpha, Guttman's lambda-2, and MSPLIT maximized split-half reliability estimates. J Educ Meas. https://doi.org/10.1111/j.17453984.1979.tb00090.x

Camps-Calvet M, Langmeyer J, Calvet-Mir L, Gómez-Baggethun E (2016) Ecosystem services provided by urban gardens in Barcelona, Spain: insights for policy and planning. Environ Sci Policy 62:14-23. https://doi.org/10.1016/j.envsci.2016.01.007

Carfora V, Caso D, Sparks P, Conner M (2017) Moderating effects of proenvironmental self-identity on proenvironmental intentions and behaviour: a multi-behaviour study. J Env Psychol 53:53925399. https://doi.org/10.1016/j.jenvp.2017.07.001

Chawla L (2020) Childhood nature connection and constructive hope: a review of research on connecting with nature and coping with environmental loss. People Nat 2:619-642. https://doi.org/10. 1002/pan3.10128

Cheng SL, Olsen W, Southerton D, Warde A (2007) The changing practice of eating: evidence from UK time diaries, 1975 and 2000. Br J Sociol 58(1):39-61. https://doi.org/10.1111/j.1468-4446. 2007.00138.x
Clayton, S. (2003). Environmental identity: a conceptual and an operational definition. In S. Clayton and S. Opotow (Eds.), Identity and the natural environment: the psychological significance of nature (p. 45-65). MIT Press

Clayton S, Myers G (2010) Conservation psychology: understanding and promoting human care for nature. Environ Conserv 37(2):222-225. https://doi.org/10.1017/S0376892910000457

Cleary A, Fielding KS, Murray Z, Roiko A (2018) Predictors of nature connection among urban residents: assessing the role of childhood and adult nature experiences. Environ Behav 52(6):579-610. https://doi.org/10.1177/0013916518811431

Colding J, Giusti M, Haga A, Wallhagen M, Barthel S (2020) Enabling relationships with nature in cities. Sustainability 12:4394. https:// doi.org/10.3390/su12114394

Cooke B, West S, Boonstra WJ (2016) Dwelling in the biosphere: exploring an embodied human-environment connection in resilience thinking. Sustain Sci 11:831-843. https://doi.org/10.1007/ s11625-016-0367-3

Cox DT, Shanahan DF, Hudson HL, Fuller RA, Gaston KJ (2018) The impact of urbanisation on nature dose and the implications for human health. Lands Urban Plan 179:72-80. https://doi.org/10. 1016/j.landurbplan.2018.07.013

Creswell JW (2009) Research design: qualitative, quantitative, and mixed methods approaches: thousand oaks. Sage Publications, CA, USA

de Kleyn L, Mumaw L, Corney H (2020) From green spaces to vital places: connection and expression in urban greening. Aust Geogr 51:205-219. https://doi.org/10.1080/00049182.2019.1686195

Dietz T, Fitzgerald A, Shwom R (2005) Environmental values. Annu Rev Environ Resour 30(1):335-372. https://doi.org/10.1146/annur ev.energy.30.050504.144444

Engemann K, Pedersen CB, Arge L, Tsirogiannis C, Mortensen PB, Svenning J-C (2019) Residential green space in childhood is associated with lower risk of psychiatric disorders from adolescence into adulthood. Proc Natl Acad Sci 116(11):5188-5193. https:// doi.org/10.1073/pnas.1807504116

Field A (2000) Discovering statistics using SPSS for windows 2000. Sage Publications, London

Folke C, Jansson A, Rockström J, Olsson P, Carpenter SR, Chapin FS, Westley F (2011) Reconnecting to the biosphere. Ambio 40(7):719-738. https://doi.org/10.1007/s13280-011-0184-y

Folke C, Biggs R, Norström AV, Reyers B, Rockström J (2016) Socialecological resilience and biosphere-based sustainability science. Ecol Soc 21(3):41. https://doi.org/10.5751/ES-08748-210341

Frantz CM, Mayer FS (2014) The importance of connection to nature in assessing environmental education programs. Stud Educ Eval 41:85-89. https://doi.org/10.1016/j.stueduc.2013.10.001

Giuliani MV, Feldman R (1993) Place attachment in a developmental and cultural context. J Environ Psychol 13:267-274

Gottwald S, Stedman RC (2020) Preserving ones meaningful place or not? Understanding environmental stewardship behaviour in river landscapes. Lands Urban Plann 198:103778. https://doi.org/10. 1016/j.landurbplan.2020.103778

Gujarati DN, Porter DC (1999) Essentials of econometrics. Irwin/ McGraw Hill, Springer

Hand KL, Freema, CC, Seddon PJ, Recio MR, Stein A, van Heeezik Y (2017) The importance of urban gardens in supporting children's biophilia. PNAS 114(2), 274-279.https://doi.org/10.1073/pnas. 1609588114

Hammitt WE (2000) The relation between being away and privacy in urban forest recreation environments. Environ Beh 32(4):521540. https://doi.org/10.1177/00139160021972649

Hartig T, Kahn PH (2016) Living in cities, naturally. Science 352(6288):938-940. https://doi.org/10.1126/science.aaf3759 
Hatty MA, Smith LDG, Goodwin D, Mavondo FT (2020) The CN-12: a brief, multidimensional connection with nature instrument. Front Psychol 11:1566. https://doi.org/10.3389/fpsyg.2020.01566

Ives CD, Giusti M, Fischer J, Abson DJ, Klaniecki K, Dorninger C, Laudan J, Barthel S, Averbetgy P, Martín-López B, Raymond CM, Kendal D, von Wehrden H (2017) Human-nature connection: a multidisciplinary review. Curr Opin Environ Sustain 26:106-113. https://doi.org/10.1016/j.cosust.2017.05.005

Ives CD, Abson DJ, von Wehrden H, Dorninger C, Klaniecki K, Fischer J (2018) Reconnecting with nature for sustainability. Sustain Sci 13(5):1389-1397. https://doi.org/10.1007/s11625-018-0542-9

Ives CD, Freeth R, Fischer J (2020) Inside-out sustainability: the neglect of inner worlds. Ambio 49:208-217. https://doi.org/10. 1007/s13280-019-01187-w

Jehlička P, Daněk P, Vávra J (2019) A change engaging resilience: home gardening, food sharing and everyday resistance. Can J Develop Stud 40(4):511-527. https://doi.org/10.1080/02255189. 2018.1498325

Jorgensen BS, Stedman RC (2006) A comparative analysis of predictors of sense of place dimensions: attachment to, dependence on, and identification with lakeshore properties. J Environ Manage 79(3):316-327. https://doi.org/10.1016/j.jenvman.2005.08.003

Kals E, Schumacher D, Montada L (1999) Emotional affinity toward nature as a motivational basis to protect nature. Environ Beh 31(2):178-202

Kingsley JY, Townsend M, Henderson-Wilson C (2009) Cultivating health and wellbeing: members' perceptions of the health benefits of a Port Melbourne community garden. Leisure Stud 28(2):207219. https://doi.org/10.1080/02614360902769894

Klaniecki K, Leventon J, Abson DJ (2018) Human-nature connectedness as a 'treatment' for pro-environmental behavior: making the case for spatial considerations. Sustain Sci 13(5):1375-1388. https://doi.org/10.1007/s11625-018-0578-x

Klaniecki K, Wuropulos K, Hager CP (2019) Behaviour change for sustainable development. In: Leal Filho W (ed) Encyclopedia of sustainability in higher education. Springer, Cham, pp 1-10

Knippenberg L, deGroot WT, vanden Born RJ, Knights P, Muraca B (2018) Relationalvalue, partnership, eudaimonia: a review. Curr Opin Environ Sustain 35:39-45. https://doi.org/10.1016/j. cosust.2018.10.022

Kowalewski D (2002) Teaching deep ecology: a student assessment. J Environ Educ 33(4):20-27. https://doi.org/10.1080/00958 960209599150

Krasny ME, Crestol SR, Tidball KG, Stedman RC (2014) New York City's oyster gardeners: memories and meanings as motivations for volunteer environmental stewardship. Lands Urban Plan 132:16-25. https://doi.org/10.1016/j.landurbplan.2014.08.003

Langemeyer J, Camps-Calvet M, Calvet-Mir L, Barthel S, GomezBaggethun E (2018) Stewardship of urban ecosystem services: understanding the value(s) of urban gardens in Barcelona. Lands Urban Plan 170:79-89. https://doi.org/10.1016/j.landurbplan. 2017.09.013

Lin BB, Fuller RA, Bush R et al (2014) Opportunity or orientation? PLoS ONE 9(1):e87422. https://doi.org/10.1371/journal.pone. 0087422

Lin BB, Philpott SM, Jha S (2015) The future of urban agriculture and biodiversity-ecosystem services: challenges and next steps. Basic Appl Ecol 16(3):189-201. https://doi.org/10.1016/j.baae. 2015.01.005

Lumber R, Richardson M, Sheffield D (2017) Beyond knowing nature: contact, emotion, compassion, meaning, and beauty are pathways to nature connection. PLoS ONE 12(5):e0177186. https://doi.org/10.1371/journal.pone.0177186

Martin J-L, Maris V, Simberloff DS (2016) The need to respect nature and its limits challenges society and conservation science. Proc Natl Acad Sci 113(22):6105-6112. https://doi. org/10.1073/pnas. 1525003113

McKenzie-Mohr D, Schultz PW (2014) Choosing effective behavior change tools. Soc Market Quart 20(1):35-46. https://doi.org/10. $1177 / 1524500413519257$

Munich (2013). Langfristige Siedlungsentwicklung (Long-term settlement development). Retrieved October 16, 2019 from https:// www.muenchen.de/rathaus/Stadtverwaltung/Referat-fuer-Stadt planung-und-Bauordnung/Projekte/Langfristige-Siedlungse ntwicklung.html

Munich (2015). Konzeptgutachten Freiraum München 2030. Entschleunigung - Verdichtung: Umwandlung (Concept report open Space Munich 2030. Deceleration - Densification - Conversion). Retrieved October 16, 2019 from https://www.muenc hen.de/rathaus/Stadtverwaltung/Referat-fuer-Stadtplanung-undBauordnung/Stadt-und-Bebauungsplanung/Gruenplanung/Freir aumentwicklung.html

Munich (2016). Münchner Krautgärten. Gemüse selber ziehen und ernten (Munichs vegetable gardens. Plant and harvest vegetables yourself). Retrieved October 16, 2019 from https://www.muenc hen.de/rathaus/dam/jcr:c9838378-8b9c-49df-bdc7-0d073ddd1e 15/flyer_krautgaerten_druck2016.pdf.

Munich (2017). Die Münchner Krautgärten: Selbsternte für Jedermann (Munich's vegetable gardens: harvest for everyone). Retrieved October 16, 2019 from https://www.muenchen.de/ rathaus/Stadtverwaltung/Referat-fuer-Stadtplanung-und-Bauor dnung/Stadt-und-Bebauungsplanung/Gruenplanung/Muenc hner-Gruenguertel/Krautg-rten.html

Munich (2018) Münchner Krautgärten - Projektentwicklung bis 2018 (Munich's vegetable gardens - project development until 2018) (unpublished document provided by the Department for Urban Planning and Building Regulation for the City of Munich)

Munich (2019). Indikatoren Atlas München (Indicator atlas Munich). Retrieved October 16, 2019 from http://www.mstatistik-muenc hen.de/indikatorenatlas/atlas.html?indicator $=i 63 \&$ date $=2018$

Naess A (1973) The shallow and the deep, long-range ecology movement. Summary Inquiry 16(1-4):95-100

Ngome I, Foeken D (2012) “"My garden is a great help"': gender and urban gardening in Buea, Cameroon. Geo J 77:103-118. https:// doi.org/10.1007/s10708-010-9389-z

Nisbet EK, Zelenski JM, Murphy SA (2009) The nature relatedness scale: Linking individuals' connection with nature to environmental concern and behavior. Environ Behav 41(5):715-740. https://doi.org/10.1177/0013916508318748

Philpott SM, Egerer MH, Bichier P, Cohen H, Cohen R, Liere H, Jha S, Li BB (2020) Gardener demographics, experience, and motivations drive differences in plant species richness and composition in urban gardens. Ecol Soc 25(4):8. https://doi.org/10. 5751/ES-11666-250408

Raymond CM, Brown G, Weber D (2010) The measurement of place attachment: personal, community, and environmental connections. J Environ Psychol 30(4):422-434. https://doi.org/10. 1016/j.jenvp.2010.08.002

Raymond CM, Giusti M, Barthel S (2017) An embodied perspective on the co-production of cultural ecosystem services: toward embodied ecosystems. J Environ Planning Manage 61(56):778-799. https://doi.org/10.1080/09640568.2017.1312300

Roach C (1991) Loving your mother: on the woman-nature relation. Hypatia 6(1):46-59. https://doi.org/10.1111/j.1527-2001.1991. tb00208.x

Robertson C (2013) The role of gender in urban agriculture: a case study of Cape Town's urban and peri-urban townships. University of Guelph, Guelph, Ontario, Canada, Thesis

Sartison K, Artmann M (2020) Edible Cities - an innovative naturebased solution for urban sustainability transformation? An explorative study of urban food production in german cities. Urban 
Forestry \& Urban Greening, vol 49 pp 126604. https://doi.org/ 10.1016/j.ufug.2020.126604

Scopelliti M, Carrus G, Adinolfi C, Suarez G, Colangelo G, Lafortezza R, Sanesi G (2016) Staying in touch with nature and well-being in different income groups: the experience of urban parks in Bogotá. Lands Urban Plan 148:139-148. https:// doi.org/10.1016/j.landurbplan.2015.11.002

Sivek DJ, Hungerford H (1990) Predictors of responsible behavior in members of three Wisconsin conservation organizations. J Environ Educ 21(2):35-40. https://doi.org/10.1080/00958964. 1990.9941929

Soga M, Gaston KJ (2016) Extinction of experience: the loss of human-nature interactions. Front Ecol Environ 14(2):94-101. https://doi.org/10.1002/fee.1225

Soga M, Gaston KJ (2020) The ecology of human-nature inter actions. Proceed Royal Soc Lond Ser B 287:2019-1882. https:// doi.org/10.1098/rspb.2019.1882

Soga M, Tsuchiya K, Evans MJ, Ishibashi So (2019) The inequalities of the extinction of experience: the role of personal characteristics and species traits in the distribution of people-plant interactions in Japan. Ecol Res 34:350-359. https://doi.org/10. 1111/1440-1703.12009

State Statistics bavaria (2019) Kreisfreie Stadt München. 09 162. Eine Auswahl wichtiger statistischer Daten (The city of Munich. 09 162. A Selection of Important Statistical Data). https://www.stati stik.bayern.de/statistikkommunal/09162.pdf

Strengers Y, Maller C (eds) (2015) Social practices, intervention and sustainability: Beyond behaviour change. Routledge, Oxon, New York

Tam K-P (2013) Concepts and measures related to connection to nature: Similarities and differences. J Environ Psychol 34:6478. https://doi.org/10.1016/j.jenvp.2013.01.004.Taylor

Turner B (2011) Embodied connections: sustainability, food systems and community gardens. Local Environ 16(6):509-522. https:// doi.org/10.1080/13549839.2011.569537

Lovell JR, Wortman STSE, Chan M (2017) Ecosystem services and tradeoffs in the home food gardens of African American, Chineseorigin and Mexican-origin households in Chicago, IL. Renew
Agricult Food Syst 32:69-86. https://doi.org/10.1017/S1742 $17051600003 \mathrm{X}$

Untied Nations (2019). World Urbanization Prospects 2018: Highlights (ST/ESA/SER.A/421). Retrieved October 16, 2019 from https:// population.un.org/wpp/

Walsh Z, Böhme J, Wamsler C (2021) Towards a relational paradigm in sustainability research, practice, and education. Ambio 50:74-84. https://doi.org/10.1007/s13280-020-01322-y

West S, Jamila Haider L, Stålhammar S, Woroniecki S (2020) A relational turn for sustainability science? Relational thinking, leverage points and transformations, Ecosystems and People, 16(1):304325. https://doi.org/10.1080/26395916.2020.1814417

Whitburn J, Linklater WL, Milfont TL (2018) Exposure to urban nature and tree planting are related to pro-environmental behavior via connection to nature, the use of nature for psychological restoration, and environmental attitudes. Environ Behav. https://doi.org/ 10.1177/0013916517751009

Whitburn J, Linklater W, Abrahamse W (2019) Meta-analysis of human connection to nature and proenvironmental behavior. Conserv Biol 34(1):180-193. https://doi.org/10.1111/cobi.13381

White MM (2011) Sisters of the soil: urban gardening as resistance in detroit. Race/Ethnicity Multidiscip Global Contexts 5(1):13-28. https://doi.org/10.2979/racethmulglocon.5.1.13

Winkler B, Maier A, Lewandowski I (2019) Urban gardening in Germany: cultivating a sustainable lifestyle for the societal transition to a bioeconomy. Sustainability 11(3):801. https://doi.org/ $10.3390 /$ su 11030801

Wolfram M, Frantzeskaki N, Maschmeyer S (2016) Cities, systems and sustainability: status and perspectives of research on urban transformations. Curr Opin Environ Sustain 22(18):e25. https:// doi.org/10.1016/j.cosust.2017.01.014

Publisher's Note Springer Nature remains neutral with regard to jurisdictional claims in published maps and institutional affiliations. 